\title{
Dislocation Reaction Mechanism for Enhanced Strain Hardening in Crystal Nano-Indentations
}

\author{
Ronald W. Armstrong $1, * \mathbb{C}$ and Wayne L. Elban ${ }^{2}$ \\ 1 Department of Mechanical Engineering, University of Maryland, College Park, MD 20742, USA \\ 2 Department of Engineering, Loyola University Maryland, Baltimore, MD 21210, USA; welban@loyola.edu \\ * Correspondence: rona@umd.edu
}

Received: 3 December 2019; Accepted: 20 December 2019; Published: 23 December 2019

\begin{abstract}
Stress-strain calculations are presented for nano-indentations made in: (1) an ammonium perchlorate (AP), $\mathrm{NH}_{4} \mathrm{ClO}_{4},\{210\}$ crystal surface; (2) an $\alpha$-iron (111) crystal surface; (3) a simulated test on an $\alpha$-iron (100) crystal surface. In each case, the calculation of an exceptionally-enhanced plastic strain hardening, beyond that coming from the significant effect of small dislocation separations in the indentation deformation zone, is attributed to the formation of dislocation reaction obstacles hindering further dislocation movement. For the AP crystal, the exceptionally-high dislocation reaction-based strain hardening, relative to the elastic shear modulus, leads to (001) cleavage cracking in nano-, micro- and macro-indentations. For $\alpha$-iron, the reaction of $(a / 2)<111>$ dislocations to form $a$ [010] Burgers vector dislocation obstacles at designated $\{110\}$ slip system intersections accounts for a higher strain hardening in both experimental and simulated nano-indentation test results. The $\alpha$-iron stress-strain calculations are compared, both for the elastic deformation and plastic strain hardening of nano-indented (100) versus (111) crystal surfaces and include important observations derived from internally-tracked $(a / 2)<010>$ Burgers vector dislocation structures obtained in simulation studies. Additional comparisons are made between the $\alpha$-iron calculations and other related strength properties reported either for bulk, micro-pillar, or additional simulated nano-crystal or heavily-drawn polycrystalline wire materials.
\end{abstract}

Keywords: nano-indentation hardness; stress-strain curves; ammonium perchlorate (AP); $\alpha$-iron; Hertzian elasticity; plastic strain hardening; dislocation density; dislocation reactions; cleavage

\section{Introduction}

Previous calculations have been presented for the (Hertzian) elastic loading behavior and follow-on plastic stress-strain curves exhibited in continuous macro- to micro- to nano-indentation hardness tests made on $\mathrm{NaCl}, \mathrm{MgO}$, and copper crystallographic surfaces [1]. Significantly higher plastic strain hardening was demonstrated for the indentation stress-strain behaviors. An especially enhanced strain hardening that was obtained for $\mathrm{MgO}$ crystals, which was tracked to the production of sessile dislocation reaction obstacles that restricted dislocation flow and eventually led to $\{110\}$ cleavage-type cracking at higher loads in micro- and macro-hardness tests [2]. More recent calculations have been presented for similar exceptionally high strain hardening, from measurements made on nano-indented tungsten crystals [3]. Here, too, the higher-level hardness stresses were attributed to the reaction of $(a / 2)<111>$ Burgers vector dislocations to form dislocations with $a<010>$ Burgers vectors that present themselves as obstacles to continuing deformation in the plastic indentation zones [3]. Such $a<010>$ Burgers vector dislocations had been proposed historically by Cottrell [4] to provide a mechanism for the observation of $\{010\}$ cleavage cracking in body-centered cubic $(b c c)$ metals. However, rather less attention has been given over the years to their having any significant role in determining the strain hardening of bcc metals. 
The purpose of the current work is to present calculations and a dislocation mechanics analysis for the elastic loading and plastic strain hardening in nano-indentation tests of two otherwise disparate crystals, that have a common connection with known cleavage cracking: (1) ammonium perchlorate, $\mathrm{NH}_{4} \mathrm{ClO}_{4}$, (AP) crystals; (2) $\alpha$-iron crystals. The calculations show that both crystals exhibit an exceptional strain hardening behavior relating to the actual or potential occurrence of cleavage cracking. Added consideration is given for $\alpha$-iron to its anisotropic elastic loading behavior and to the assessment of the dislocation types and densities accompanying simulated nano-indentations made with much smaller spherical indenter tips [5]. The hardness calculations are also compared with measurements derived from other types of external test and internal structure descriptions.

\section{Nano-, Micro- and Macro-Indentations on AP}

The continuous nano-indentation load, $\mathrm{P}$, dependence on penetration depth, $\mathrm{h}$, for a spherically-tipped Berkovich diamond indenter impressed onto an AP (-210) crystal surface was investigated by Lucca, Klopfstein, Mejia, Rossettini and DeLuca [6]. Figure 1 shows a superposition of two indentation trajectories. The relatively faint loading curve marked for the first indentation is seen to exhibit a continuing series of pop-in displacements during the progressive plastic deformation, whereas a second indentation placed near to the first one exhibits a smoother trajectory. The inserted enlargement of the initial loading record for the second indent shows that a rather smooth departure from elastic loading had occurred before an obvious first pop-in event.

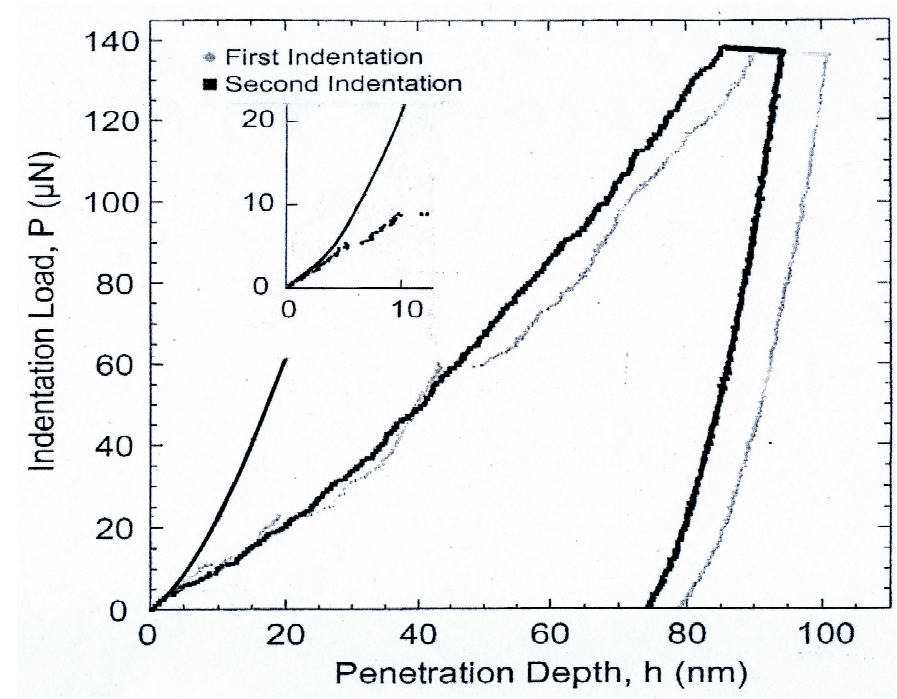

Figure 1. Composite graph for two nano-indentation $\mathrm{P}-\mathrm{h}$ trajectories obtained in tests performed on a (-210) AP crystal surface; as adapted from the measurements reported in Ref [6].

The elastic deformation curve in the inset figure and in the larger overall displacement record has been fitted with a Hertzian dependence of $\mathrm{P}$ on $\mathrm{h}$ in accordance with the relationship:

$$
\mathrm{P}=(\sqrt{ }[8 \mathrm{D}] / 3) \mathrm{E}_{\mathrm{r}} \mathrm{h}^{3 / 2}
$$

In Equation (1), $D$ is the diameter of the indenter tip and the factor $E_{r}=\left\{\left[\left(1-v_{b}^{2}\right) / E_{b}\right]+[(1-\right.$ $\left.\left.\left.v_{s}^{2}\right) / E_{s}\right]\right\}^{-1}$ is the reduced elastic modulus that is expressed in terms of Poisson's ratio, $v_{i}$ and Young's modulus, $\mathrm{E}_{\mathrm{i}}$ for both ball indenter and crystal specimen. With $v_{\mathrm{b}}, \mathrm{E}_{\mathrm{b}}$ taken as $0.072,1143 \mathrm{GPa}$ for the diamond tip and $v_{s}, E_{s}$ as $0.30,20 \mathrm{GPa}$ for the AP crystal, a value of $E_{\mathrm{r}}=21.6 \mathrm{GPa}$ is computed. Lucca et al. had determined an average value of $E_{r}=19.5 \mathrm{GPa}$ for the tests from an analysis of the plastic unloading curves obtained for indentation depths ranging from 35 to $125 \mathrm{~nm}$. For the current work, the $\mathrm{P}-\mathrm{h}$ data in Figure 1 were digitized, and a value of $\mathrm{E}_{\mathrm{r}}=20.5 \mathrm{GPa}$ was employed to give 
a fitted indenter tip diameter, $\mathrm{D}=1300 \mathrm{~nm}$ for the experiment, much smaller than a $\mathrm{D}$ of $\sim 6 \mu \mathrm{m}$ that had been estimated by Lucca et al. for the elastic loading behavior.

The linear elastic contact stress dependence on strain for the initial dependence of $P$ on $h$ has been described previously [1]. The contact stress, $\sigma_{\mathrm{e}}$, is specified either directly in terms of the coordinate values of $\left(h_{e}, P\right)$ or from the Hertzian relationship in the equivalent expressions:

$$
\sigma_{\mathrm{e}}=2 \mathrm{P} / \pi \mathrm{h}_{\mathrm{e}} \mathrm{D}=(4 \sqrt{ } 2 / 3 \pi) \mathrm{E}_{\mathrm{r}}\left(\mathrm{h}_{\mathrm{e}} / \mathrm{D}\right)^{1 / 2}
$$

The corresponding elastic strain, $\varepsilon_{\mathrm{e}}$, is specified by the ratio of contact diameter, $\mathrm{d}_{\mathrm{e}}$, and $\mathrm{D}$ as

$$
\varepsilon_{\mathrm{e}}=\left(\mathrm{d}_{\mathrm{e}} / \mathrm{D}\right)=\left(2 \mathrm{~h}_{\mathrm{e}} / \mathrm{D}\right)^{1 / 2}
$$

The follow-on plastic part of the stress-strain behavior is based on a rigid ball approximation for the indenter tip for which the plastic stress, $\sigma_{\mathrm{p}}$, is similarly expressed [1] as

$$
\sigma_{\mathrm{p}}=4 \mathrm{P} /\left(\pi \mathrm{d}_{\mathrm{p}}{ }^{2}\right)=\mathrm{P} /\left(\pi \mathrm{h}_{\mathrm{p}} \mathrm{D}\left[1-\left(\mathrm{h}_{\mathrm{p}} / \mathrm{D}\right)\right]\right)
$$

In Equation (4), $d_{p}$ is the projected diameter of the indent on the crystal surface and $h_{p}$ is the total value, $h$, for the indenter penetration under load. Thus, the related plastic strain is $\left(d_{p} / D\right)=(d / D)$ as

$$
\left(\mathrm{d}_{\mathrm{p}} / \mathrm{D}\right)=2\left[\left(\mathrm{~h}_{\mathrm{p}} / \mathrm{D}\right)\left(1-\left(\mathrm{h}_{\mathrm{p}} / \mathrm{D}\right)\right]^{1 / 2}\right.
$$

The resultant elastic-plastic stress-strain calculations corresponding to the digitized $\mathrm{P}-\mathrm{h}$ dependencies obtained for the two curves in Figure 1 are shown as open or closed circle points in Figure 2, that also contains additional measurements to be described for a range of diamond pyramid hardness values as open square points [7], and for a continuous steel ball loading test with $\mathrm{D}=1.5875$ $\mathrm{mm}$, as inverted triangle points [8]. In [7], a detailed description was given of the particular dislocation reactions required to occur at observed slip system intersections surrounding the indentation sites.

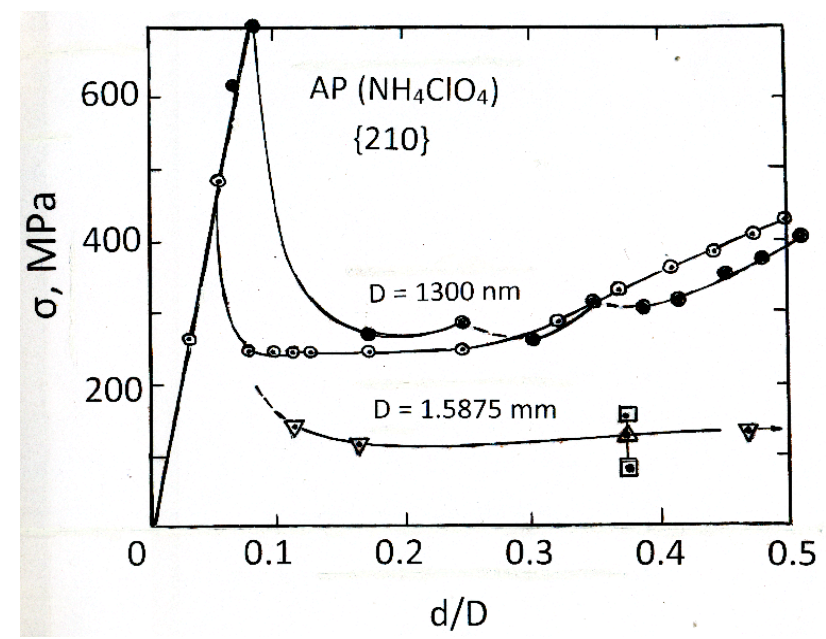

Figure 2. Elastic-plastic stress-strain calculations for two nano-indents in AP [6], also in comparison with other (open square and triangle) diamond pyramid micro-hardness [7,8] and (inverted triangle) steel ball macro-hardness [8] measurements.

In Figure 2, the lowest elastic open circle point for the direct calculation of the stress specified in Equation (2) corresponds in Figure 1 to a digitized coordinate of $\left(\mathrm{h}_{\mathrm{e}}, \mathrm{P}\right)=(0.6 \mathrm{~nm}, 0.324 \mu \mathrm{N})$. The highest closed circle elastic stress corresponds to $\left(h_{e}, P\right)=(5.0 \mathrm{~nm}, 7.14 \mu \mathrm{N})$. The elastic stress computations are seen to fall on the Hertzian line determined using Equation (2) in accordance with the value $\mathrm{E}_{\mathrm{r}}$ $=20.5 \mathrm{GPa}$. A relatively smooth plastic portion of the stress-strain curve is obtained for the second 
indentation as compared with the progression of displacement "jumps" matched with the succession of mini-pop-in displacements recorded for the first indentation. For both post-yield stress-strain dependencies, a relatively constant plastic flow stress is initially obtained, then followed by a region of relatively strong strain hardening, $\Delta \sigma_{\mathrm{p}} / \Delta \varepsilon_{\mathrm{p}}$. A linear approximation to the strain hardening shown in Figure 2 gives $\Delta \sigma_{\mathrm{p}} / \Delta \varepsilon_{\mathrm{p}}=0.6 \mathrm{GPa}$. The strain hardening is converted [1] to a strain hardening coefficient in a compression test $\left(\Delta \sigma_{\mathrm{c}} / \Delta \varepsilon_{\mathrm{c}}\right)$ by multiplying by a factor of $(5 / 3)$ to give an equivalent strain hardening coefficient of $1.0 \mathrm{GPa}$. On either basis, the strain hardening coefficient is very high, say compared to the AP elastic shear modulus, G, of 7.07 GPa [9].

Support for the expectation of an exceptional strain hardening within the nano-scale plastic zone is provided by Lucca et al. [6] having reported slip-induced $\{001\}$ cracking at their nano-indentations. Elban and Armstrong [7] had attributed the same cleavage-like cracking observed in diamond pyramid micro-indentation tests to sessile dislocation reactions occurring at the intersection of juxtaposed $\{111\}$ slip systems in accordance with the relationship:

$$
(a / 2)[-10-1]_{(-111)}+(a / 2)[10-1]_{(-11-1)} \rightarrow a[00-1]_{(00-1)}
$$

The vertical range of open-square points shown at an effective $(d / D)=0.375$ in Figure 2 had been established by the investigation of the load dependence for such cracking [7, 8]. A decreasing hardness was obtained for increase in load from $0.01 \mathrm{~N}$ to $1.0 \mathrm{~N}$ and a corresponding increase in crack length that followed a fracture mechanics (3/2) dependent of $\mathrm{P}$ on crack length. The same type $\{001\}$ cracking was observed for the inverted triangle points shown in Figure 2 as obtained from a continuous macro-steel-ball test [8]. In a study of thermal stresses induced in AP by the impact of a laser beam, the $\{001\}$ cracking in the (low temperature) orthorhombic structure was related to a same type $\{001\}$ cracking that occurred on a much finer micro-scale in the higher temperature polymorphic face-centered cubic structure [10]. Despite the elastic anisotropy expected for its orthorhombic crystal structure, the $\mathrm{G}=7.07 \mathrm{GPa}$ and $\mathrm{E}=18.09 \mathrm{GPa}$ reported for $\mathrm{AP}$ in a recent determination of elastic constants [9], combine in an isotropic relation to give a reasonable Poisson's ratio of 0.28.

\section{Experimental and Simulated Nano-Indentation Hardness of $\alpha$-Iron Crystals}

Araki, Mashima, Masumura, Tsuchiyama, Takaki and Ohmura [11] presented nano-indentation test measurements made on interior $\alpha$-iron grains of a polycrystalline material with (111) crystal surfaces. The purpose was to make a comparison with same test measurements obtained on the material grain boundaries. Elastic-plastic stress-strain calculations for the $\mathrm{P}-\mathrm{h}$ measurements are given as one part of Figure 3. A value of $\mathrm{D}=1100 \mathrm{~nm}$ was determined for the well-defined elastic loading behavior.

Also included in Figure 3 are same-type calculations made for a simulated nano-indentation test run by Alhafez et al. [5] on a 'defective' $\alpha$-iron (100) crystal surface. A value of $\mathrm{D}=20 \mathrm{~nm}$ was employed for the simulated test in which case the defective crystal, with average dislocation line separation of $7.5 \mathrm{~nm}$, was shown to exhibit gradual plastic yielding as compared with an appreciably enhanced pop-in behavior that was obtained for a simulated dislocation-free crystal. Correspondingly, a value of the Hertzian elastic contact diameter, $d_{e}=\left[2 h_{e} D\right]^{1 / 2}=7.1 \mathrm{~nm}$, was obtained at the limiting elastic load value for the defective crystal. The cross-hatched range in stress at the right-side ordinate axis in Figure 3 gives indication of the progressive hardening for the defective crystal until reaching a value of $(\mathrm{d} / \mathrm{D})=1.0$ in the simulated test. 


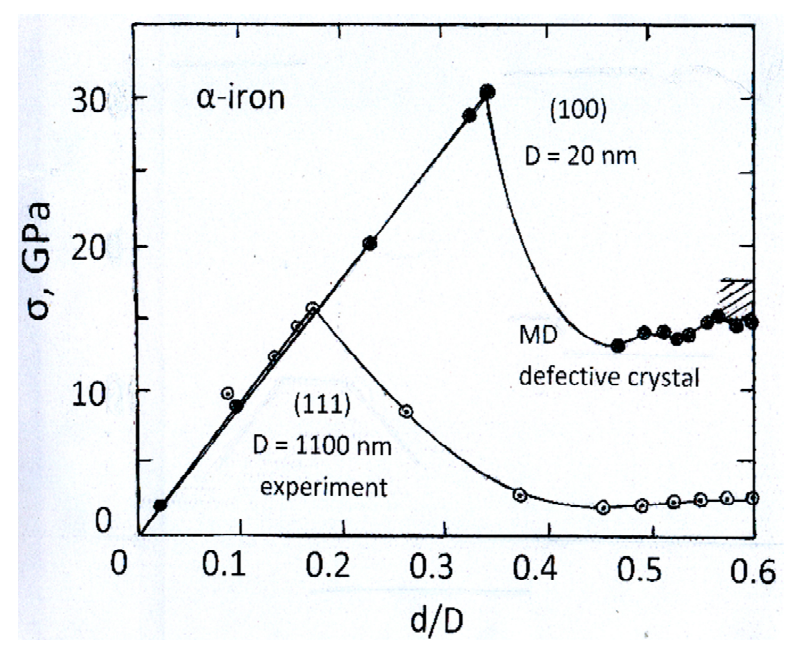

Figure 3. Experimental [11] and simulated [5] nano-indentation stress-strain dependencies calculated for $\alpha$-iron (111) and (100) crystal surfaces employing different respective D values of 1100 and $20 \mathrm{~nm}$.

\subsection{Comparison of Hertzian Elastic Loading Behaviors}

The near equivalent determinations for Figure 3 of $E_{r}=213 \mathrm{GPa}$ for the Alhafez et al. [5] simulated test result as compared with $\mathrm{E}_{\mathrm{r}}=224.5 \mathrm{GPa}$ for the Araki et al. [11] experimental test is surprising on the basis of the elastic anisotropy of $\alpha$-iron, separate from Alhafez et al. having employed a rigid indenter. For example, average values of $\mathrm{E}_{111}=239.5 \mathrm{GPa}$ and $\mathrm{E}_{100}=136 \mathrm{GPa}$ are obtained from recently reported elastic constants [12,13]. The elastic anisotropy of $\alpha$-iron is similar to that of copper for which Dub, Lim and Chaudhri [14] had shown an expected significant difference in experimental (111) and (100) P - h elastic dependencies. The reason for the seemingly-anomalous near-equivalence of the experimental and simulated elastic stiffness for the two crystal surfaces in the current case is tracked to the molecular dynamics (MD) method of calculation for the atomistic simulation [5].

Earlier, Ruestes, Stukowski, Tang, Tramontina et al. [15] had investigated the importance of choosing appropriate interatomic potentials among other parameters in assessing the simulated nano-indentation behavior of another bcc metal, tantalum. Goel, Cross, Stukowski, Gamsjäger, Beake and Agrawal [16] have also reported on the design aspects of simulated nano-indentation tests, with application to simulated and experimental tests on (isotropic) bcc tungsten. For modeled diamond indentation at $10 \mathrm{~K}$ of a (100) tungsten crystal surface, a higher $E_{\mathrm{r}}$ than the extrapolated experimental value was obtained, seemingly consistent with the Alhafez et al. [5] result based on comparison with the (111) experimental $\alpha$-iron value. Vlassak and Nix [17] have modeled on a continuum basis the elastic deformation modulus for unloading in an indentation test in terms of either a rigid circular punch or a paraboloid indenter shape for which the effect of elastic anisotropy on $E_{r}$, past the appearance of Poisson's ratio in Equation (1), is significantly reduced. For an anisotropy factor of 3.26 for $\alpha$-iron [18], an indentation modulus ratio of $\left(\mathrm{E}_{111} / \mathrm{E}_{100}\right)=1.12$ would be obtained based on their analysis, compared to the ratio of 1.05 for the near equivalent elastic slopes in Figure 3. Filippov and Koch [19] have employed the Vlassak and Nix analysis to describe a reduced elastic modulus anisotropy measured on unloading of relatively-deep diamond pyramid nano-indentations impressed in $\{100\},\{110\}$ and $\{111\}$ aluminum crystals surfaces.

\subsection{Plastic Yielding and Strain Hardening}

Plastic yielding in a nano-indentation hardness test has been shown to occur at a relatively high stress level independent of whether pop-in or gradual plastic yielding is exhibited [3]. The upper-limiting elastic contact stress, $\sigma_{\mathrm{e}}$, for the experimental calculation in Figure 3 of 15.6 GPa was determined by both methods of stress evaluation indicated in Equation (2). Araki et al. [11] 
had obtained a corresponding relatively low shear stress of $\sim 6 \mathrm{GPa}$ for the $\mathrm{P}-\mathrm{h}$ measurement on a Hertzian basis and attributed the result to dislocation nucleation and multiplication.

Table 1 provides a comparison of the experimental Araki et al. [11] test parameters with those obtained in simulated tests on $\alpha$-iron by Alhafez et al. [5] and in two other model simulations [19,20]. The table includes, for the employment of different $D$ values, the limiting elastic contact stress, $\sigma_{\mathrm{e}}$; pop-in stress, $\sigma_{\text {pop-in; }}$ and comparable strain hardening coefficient in compression, $\left(\Delta \sigma_{\mathrm{c}} / \Delta \varepsilon_{\mathrm{c}}\right)=(5 / 3)\left(\Delta \sigma_{\mathrm{p}} / \Delta \varepsilon_{\mathrm{p}}\right)$ at an effective compressive strain, $\varepsilon_{\mathrm{c}}$.

Table 1. Comparison of $\alpha$-iron nano-indentation crystal hardness stresses and strain hardening.

\begin{tabular}{cccccccc}
\hline Reference & Crystal & $\begin{array}{c}\mathbf{D} \\
\mathbf{N m}\end{array}$ & $\begin{array}{c}\boldsymbol{\sigma}_{\mathbf{e}} \\
\mathbf{G P a}\end{array}$ & $\begin{array}{c}\boldsymbol{\sigma}_{\text {pop-in }} \\
\mathbf{G P a}\end{array}$ & $(\mathbf{d} / \mathbf{D})_{\text {pop-in }}$ & $\begin{array}{c}\left(\Delta \boldsymbol{\sigma}_{\mathbf{c}} / \Delta \varepsilon_{\mathbf{c}}\right) \\
\mathbf{G P a}\end{array}$ & $\mathcal{E}_{\mathbf{c}}$ \\
\hline Araki et al. [11] & $(111)$ & 1100 & 15.6 & 1.98 & 0.45 & 6.04 & 0.11 \\
Lu et al. [20] & $(111)$ & 200 & 37.4 & 8.80 & 0.60 & 39 & 0.15 \\
Alhafez et al. [5] & $(111)$ & 20 & 30.45 & 14.0 & 0.34 & 23.6 & 0.11 \\
Kositski and & $(110)$ & 10 & 37.4 & 19.6 & 0.44 & 17.1 & 0.18 \\
Mordehai [21] & & & & & & & \\
\hline
\end{tabular}

The higher level of the yield stresses proceeding downward in the list of smaller D values in Table 1 is attributed to the requirement for generation of dislocation loops of smaller size in the relatively perfect nano-scale contact zones, hence the purpose of Alhafez et al. [5] investigating perfect and (dislocation-containing) 'defective' crystals in their simulations. The relatively high contact stress of $30.45 \mathrm{GPa}$ at $\varepsilon_{\mathrm{e}}=0.35$ for gradual yielding of the defective crystal was compared in the Alhafez et al. investigation with an even higher elastic contact stress of $46 \mathrm{GPa}$ at onset of pop-in behavior at $\varepsilon_{\mathrm{e}}$ $=0.48$, then leading to a pop-in stress and subsequent strain hardening near to that obtained for the defective crystal. Armstrong and Elban [1] have given emphasis to the subsequent plastic strain hardening coefficient being higher because of the small dislocation line lengths associated with the continuing dislocation interactions. A favorable comparison was provided in [1] of greater crystal strengths being measured at nano-scale dimensions of metal 'whiskers', 'pillars' and nano-grain size polycrystalline materials.

Table 2 provides the referenced comparison of nano-scale and conventional tension or compression measurements. Separate yield stress measurements of $0.12-0.18 \mathrm{GPa}$ had been reported [22] for the same bulk "as annealed" $\alpha$-iron material for a corresponding polycrystalline grain size range of 53-16 $\mu \mathrm{m}$. A tensile flow stress, $\sigma_{\varepsilon}$, of $0.25 \mathrm{GPa}$ was obtained at a strain, $\varepsilon_{\mathrm{t}}=0.11$, to compare at the same strain value with $\left(\sigma_{\mathrm{p}} / 3\right)=0.66 \mathrm{GPa}$ for the experimental curve in Figure 3. In a comparison of the nano-indentation strain hardening on a compression test basis, $\left(\Delta \sigma_{\mathrm{c}} / \Delta \varepsilon_{\mathrm{c}}\right)=6.04 \mathrm{GPa}$ is seen to be more than an order of magnitude greater than the value of 0.20 measured for the conventional polycrystalline material at a same value of tensile strain, $\varepsilon_{t}=0.11$. The calculations compare with the far larger simulated strain hardening in Table 1 of 23.6 GPa estimated from Figure 3 for the results of Alhafez et al. [5], as associated with the 55 times smaller nano-scale value of $\mathrm{D}=20 \mathrm{~nm}$. 
Table 2. Comparison of $\alpha$-iron nano-indentation and other material property parameters.

\begin{tabular}{|c|c|c|c|c|c|c|}
\hline Reference & Condition & $\begin{array}{c}\sigma_{\varepsilon} \\
\mathrm{GPa}\end{array}$ & $\begin{array}{c}{ }^{*} \mathrm{D}, \ell, d \\
\mathrm{Nm}\end{array}$ & $\varepsilon_{\mathrm{i}}$ & $\begin{array}{c}\Delta \sigma_{\mathrm{c}} / \Delta \varepsilon_{\mathrm{c}} \\
\mathrm{GPa}\end{array}$ & $\begin{array}{c}\sigma_{\varepsilon} \\
\text { GPa }\end{array}$ \\
\hline Araki et al. [5] & $\begin{array}{c}(111) \\
\text { Nano-indent }\end{array}$ & $\left(\sigma_{\mathrm{p}} / 3\right): 0.66$ & D: 1100 & $\varepsilon_{\mathrm{C}}: 0.11$ & 6.04 & 0.95 \\
\hline Araki et al. [22] & Bulk Tension & $\sigma_{t}: 0.25$ & $\ell: 1600$ & $\varepsilon_{\mathrm{t}}: 0.11$ & 0.20 & 0.28 \\
\hline Purcek et al. [23] & ECAP Tension & $\sigma_{t}: 0.69$ & $\ell: 240$ & $\varepsilon_{\mathrm{t}}: 0.009$ & 4.14 & 0.79 \\
\hline $\begin{array}{l}\text { Rogne and } \\
\text { Thaulow [24] }\end{array}$ & $\begin{array}{l}\text { Micro-pillar } \\
\text { Compression }\end{array}$ & $\sigma_{\mathrm{c}}: 1.9$ & $d: 150$ & $\varepsilon_{\mathrm{c}}: 0.05$ & 25 & 2.75 \\
\hline Li et al. [25] & $\begin{array}{l}\text { Drawn Wire } \\
\text { Tension }\end{array}$ & $\sigma_{\mathrm{t}}: 6.5$ & $\ell: 9$ & $\varepsilon_{\mathrm{t}}: 0.095$ & 74 & 6.5 \\
\hline $\begin{array}{l}\text { Kositski and } \\
\text { Mordehai [21] }\end{array}$ & $\begin{array}{l}\text { MD Nano-wire } \\
\text { Compression }\end{array}$ & $\sigma_{\mathrm{c}}: 7.5$ & $d: 5$ & $\varepsilon_{\mathrm{C}}: 0.10$ & 105 & 18 \\
\hline
\end{tabular}

${ }^{*} \mathrm{D}$ is indenter tip diameter; $\ell$ is grain diameter; and $d$ is pillar or wire diameter.

\section{Discussion}

The exceptionally higher nano-indentation stresses and especially the significantly higher strain hardening coefficients obtained both for the current (111) and (100) $\alpha$-iron crystal surfaces-as well as for the earlier-described AP strength properties described for $\{210\}$ crystal surfaces-relative to microand macro-indentation properties or test measurements on conventional bulk materials, relate generally to the particular higher stress environments involved with the much smaller dislocation line lengths that are operative at nano-scale dimensions [26,27]. A main contribution to the higher strength values has been more often associated therefore with the Taylor theory of flow stress dependence on the dislocation density. Zhao, Mayer, He and Zhang [28] have provided an important review of the corresponding initiation of plasticity and evolution of dislocation density in such tests, including an assessment of MD simulations for $\alpha$-iron. Such high stresses are even associated in their assessment with an early occurrence of deformation twinning. In the current work, we draw attention again to the importance of dislocation reaction obstacles that produce resistance to the nano-scale deformation and even leading to cleavage cracking as demonstrated previously for $\mathrm{MgO}$ [1] and now for AP crystals. The indentation tests done thus far have apparently fallen short of producing $\{010\}$ cracking in $\alpha$-iron.

Such earlier-referenced attribution in [3] of reacted \{010\} Burgers vector dislocations being responsible for an exceptional hardness of nano-indented (111) tungsten crystal surfaces was derived on a stereographic-projection-based description of $(a / 2)<111>$ Burgers vector dislocations intersecting on adjacent $\{110\}$ slip systems in accordance with the reaction:

$$
(a / 2)[-111]_{(110)}+(a / 2)[11-1]_{(011)} \rightarrow a[010]_{(-101)}
$$

The reaction arrow in Equation (7) points to the right because the reaction occurring along the intersection of the $\{110\}$ slip planes is favorable based on the dislocation self-energies. Such reactions occur in line with the three-fold symmetry of the (111) crystal surface. Connection of the dislocation reaction to other descriptions of bcc cleavage behaviors has been described in [3]. For the four-fold symmetry of the nano-indented (100) crystal surface in the simulated experiment of Alhafez et al. [5], the same type dislocation reactions occur as for Equation (7). An illustrative example is expressed based on the same standard stereographic projection as

$$
(a / 2)[11-1]_{(101)}+(a / 2)[-1-1-1]_{(110)} \rightarrow a[00-1]_{(11-1)}
$$

In this case, the reacted dislocation has a [1-10] line vector. Other similar type reactions occurring between juxtaposed $\{110\}$ planes, such as (110) and (1-10), would produce reacted dislocations with [001] Burgers vectors perpendicular to the (001) crystal surface.

Evidence of a particular case of $<100>$ Burgers vector dislocations being produced at the earliest stage of a simulated nano-indentation has been found in the color-coded dislocation images reported 
by Goel et al. [16]. In addition, Alhafez et al. [5] have tracked the Burgers vectors of dislocations produced in their simulations and found substantial dislocation line lengths having $<010\rangle$ Burgers vectors, including the very interesting observation of an increase in effective density of the $<010>$-type dislocations on unloading the specimen, hence providing important evidence for the earmarked dislocation reaction being an energetically favorable one. Thus, these reacted pre-crack and otherwise obstacle-type dislocations that are unfavorable for deformation by slip are concluded to constitute an important strain hardening contribution for the AP and $\alpha$-iron crystals examined in the current work.

\section{Summary}

Elastic-plastic stress-strain calculations are presented for macro-, micro- and nano-indented AP crystals and for both experimental and simulated nano-indentation tests performed on $\alpha$-iron crystal surfaces. The calculations demonstrate that, beyond the occurrence of a higher yield stress for initial plasticity, an especially-enhanced follow-on plastic strain hardening has occurred in both crystals. The enhanced strain hardening has occurred without significant initial pop-in behavior and, for the simulated tests on $\alpha$-iron, is independent of an apparent difficulty in quantitatively predicting the elastic loading behavior. The cause of the strain hardening is tracked to the deformation-induced occurrence of specific $<010>$ Burgers vector dislocation reactions that resist further plastic deformation. In AP, the $<010>$ dislocation reaction-based hardening leads to $\{001\}$-type cleavage cracking. For the simulated experiment on $\alpha$-iron, the dislocation density measurements of such reacted $<010>$ Burgers vector dislocations are supported by an important observation obtained from a separate nano-indentation test simulation. It is interesting that such internal structural observations, that are demonstrated to effect the exceptional strain hardening, were associated historically with the Cottrell dislocation reaction mechanism of explaining $\{010\}$ cleavage cracking in $\alpha$-iron and other bcc metals at lower temperatures or higher loading rates.

Author Contributions: Both authors contributed equally to the work. All authors have read and agreed to the published version of the manuscript.

Funding: This research received no external funding.

Acknowledgments: S.M. Walley and C.J. Ruestes are thanked for correspondence on the work and for providing helpful references.

Conflicts of Interest: The authors declare no conflict of interest.

\section{References}

1. Armstrong, R.W.; Elban, W.L. Exceptional crystal strain hardening determined over macro- to micro- to nano-size scales in continuous spherical indentation tests. Mater. Sci. Eng. A 2019, 757, 95-100. [CrossRef]

2. Armstrong, R.W.; Wu, C.C. Lattice mis-orientation and displaced volume for micro-hardness indentations in MgO crystals. J. Am. Ceram. Soc. 1978, 61, 102-106. [CrossRef]

3. Armstrong, R.W.; Elban, W.L. Tungsten (111) crystal strain hardening in nano-indentations. Int. J. Refract. Met. Hard Mater. 2019. [CrossRef]

4. Cottrell, A.H. Theory of brittle fracture in steel and similar metals. Trans. TMS-AIME 1958, 212, 1089-1127.

5. Alhafez, I.A.; Ruestes, C.J.; Bringa, E.M.; Urbassek, H.M. Influence of pre-existing plasticity on nano-indentation-An atomistic analysis of the dislocation fields produced. J. Mech. Phys. Solids 2019, 132, 103674. [CrossRef]

6. Lucca, D.A.; Klopfstein, M.J.; Mejia, O.R.; Rossettini, L.; DeLuca, L.T. Investigation of ammonium perchlorate by nano-indentation. Mater. Sci. Technol. 2006, 22, 396-401. [CrossRef]

7. Elban, W.L.; Armstrong, R.W. Plastic anisotropy and cracking at hardness impressions in single crystal ammonium perchlorate. Acta Mater. 1998, 46, 6041-6052. [CrossRef]

8. Elban, W.L.; Sandusky, H.W.; Beard, B.C.; Glancy, B.C. Microstructural basis for enhanced shock-induced chemistry in single crystal ammonium perchlorate. J. Propuls. Power 1995, 11, 24-31. [CrossRef]

9. Liu, B.; Wang, X.-J.; Bu, X.Y. First principles investigations of structural, electronic and elastic properties of ammonium perchlorate under high pressures. Acta Phys. Sin. 2016, 65, 126102. [CrossRef] 
10. Ramaswamy, A.L.; Shin, H.; Armstrong, R.W.; Lee, C.H. Nano-second and pico-second laser-induced cracking and ignition of single crystals of ammonium perchlorate. J. Mater. Sci. 1996, 31, 6035-6042. [CrossRef]

11. Araki, S.; Mashima, K.; Masumura, T.; Tsuchiyama, T.; Takaki, S.; Ohmura, T. Effect of grain boundary segregation of carbon on critical grain boundary strength of ferritic steel. Scr. Mater. 2019, 169, 38-41. [CrossRef]

12. Cantara, A.M.; Zecevic, M.; Eghtesad, A.; Poulin, C.M.; Knezevic, M. Predicting elastic anisotropy of dual-phase steels based on crystal mechanics and microstructure. Int. J. Mech. Sci. 2019, 151, 639-649. [CrossRef]

13. Diehl, M.; Niehuesbernd, J.; Bruder, E. Quantifying the contribution of crystallographic texture and grain morphology on the elastic and plastic anisotropy of bcc steel. Metals 2019, 9, 1252. [CrossRef]

14. Dub, S.N.; Lim, Y.Y.; Chaudhri, M.M. Nano-hardness of high purity Cu (111) single crystals: The effect of indenter load and prior plastic strain. J. Appl. Phys. 2010, 107, 043510. [CrossRef]

15. Ruestes, C.J.; Stukowski, A.; Tang, Y.; Tramontina, D.R.; Erhart, P.; Remington, B.A.; Urbassek, H.M.; Meyers, M.A.; Bringa, E.M. Atomic simulation of tantalum nano-indentation: Effects of indenter diameter, penetration velocity, and interatomic potentials on defect mechanisms and evolution. Mater. Sci. Eng. A 2014, 613, 390-403. [CrossRef]

16. Goel, S.; Cross, G.; Stukowski, A.; Gamsjäger, E.; Beake, B.; Agrawal, A. Designing nano-indentation simulation studies by appropriate indenter choices: Case study on single crystal tungsten. Comput. Mater. Sci. 2018, 152, 196-210. [CrossRef]

17. Vlassak, J.J.; Nix, W.D. Indentation modulus of elastically anisotropic half spaces. Philos. Mag. A 1993, 67, $1045-1056$. [CrossRef]

18. Hirth, J.P.; Lothe, J. Theory of Dislocations, 1st ed.; McGraw-Hill Book Co.: New York, NY, USA, 1968; pp. 761-762.

19. Filippov, P.; Koch, U. Nano-indentation of aluminum single crystals: Experimental study on influencing factors. Materials 2019, 12, 3688. [CrossRef]

20. Lu, C.; Gao, Y.; Michal, G.; Deng, G.; Huynh, N.N.; Zhu, H.; Liu, X.; Tieu, A.K. Experiment and molecular dynamics simulation of nano-indentation of body-centered cubic iron. J. Nanosci. Nanotechnol. 2009, 9, 7307-7313. [CrossRef]

21. Kositski, R.; Mordehai, D. Role of dislocation pile-ups in nucleation-controlled size-dependent strength of Fe nano-wires. Acta Mater. 2017, 136, 190-201. [CrossRef]

22. Araki, S.; Fuji, K.; Akama, D.; Tsuchiyama, T.; Takaki, S.; Ohmura, T.; Takahashi, J. Effect of low temperature aging on Hall-Petch coefficient in ferritic steels containing a small amount of carbon and nitrogen. ISIJ Int. 2018, 58, 1920-1926. [CrossRef]

23. Purcek, G.; Saray, O.; Karaman, I.; Maier, H.J. High strength and high ductility of ultrafine-grained interstitial-free steel produced by ECAE and annealing. Metal. Mater. Trans. A 2012, 43A, 1884-1894. [CrossRef]

24. Rogne, B.R.S.; Thaulow, C. Strengthening mechanisms of iron micro-pillars. Philos. Mag. A 2015, 95, 1814-1828. [CrossRef]

25. Li, Y.; Raabe, D.; Herbig, M.; Choi, P.-P.; Goto, S.; Kostka, A.; Yarita, H.; Borchers, C.; Kirchheim, R. Segregation stabilizes nano-crystalline bulk steel with near theoretical strength. Phys. Rev. Lett. 2014, 113, 106104. [CrossRef]

26. Armstrong, R.W. Crystal engineering for mechanical strength at nano-scale dimensions. Crystal 2017, 7, 315. [CrossRef]

27. Shahbeyk, S.; Voyiadjis, G.Z.; Habibi, V.; Astaneh, S.H.; Yaghoobi, M. Review of size effects during micro-pillar compression test: Experiments and atomistic simulations. Crystal 2019, 9, 591. [CrossRef]

28. Zhao, K.; Mayer, A.E.; He, J.; Zhang, Z. Dislocation-based plasticity in the case of nano-indentation. Int. J. Mech. Sci. 2018, 148, 158-173. [CrossRef]

(C) 2019 by the authors. Licensee MDPI, Basel, Switzerland. This article is an open access article distributed under the terms and conditions of the Creative Commons Attribution (CC BY) license (http://creativecommons.org/licenses/by/4.0/). 